\title{
Severe refractory non-islet cell hypoglycaemia due to metastatic colorectal carcinoma
}

M Ganguri, J Abbas, S Zhyzhneuskaya, A Ramdas, S Nag - The James Cook University Hospital, Middlesbrough

\section{Introduction}

-Non-islet cell tumour hypoglycaemia (NICTH) is an uncommon but serious complication of disseminated malignancy

-The underlying aetiology of hypoglycaemia is tumoral overproduction of IGF-II, which results in stimulation of insulin receptors and increased glucose utilization

- Extensive tumour burden involving the liver and adrenal glands can also cause severe hypoglycaemia.

\section{Case report}

-An 80 yr old man presented acutely in an unresponsive state. Capillary glucose was recorded as $1.1 \mathrm{mmol} / \mathrm{l}$. He had no history of diabetes and had no access to oral hypoglycaemic agents. Marked Hepatomegaly, deranged liver functions (ALT 48 u/L, ALP 894 u/L, GGT $1262 \mathrm{u} / \mathrm{L}$ ) and coagulopathy (Prothrombin time 15.8 secs) were noted

- Abdominal ultrasound showed hepatic metastases and subsequent staging CT scan confirmed a primary colorectal malignancy with extensive hepatic metastases.

-Severe hypoglycaemia was initially managed with a continuous $20 \%$ Dextrose infusion. Diazoxide 200mg BD was initiated but despite this and concurrent Dextrose, capillary glucose remained low $(<4 \mathrm{mmol} / \mathrm{l})$.

-Prednisolone $60 \mathrm{mg}$ once daily and subcutaneous Octreotide $50 \mathrm{mcg}$ three times a day were subsequently initiated but despite this hypoglycaemia proved difficult to control.

-Serum C-peptide $(<0.10 \mathrm{nmol} / \mathrm{l})$ and Insulin (<1.0) were appropriately suppressed in keeping with NICTH. Adrenal insufficiency was excluded as a potential cause of hypoglycaemia. Despite maximal combined therapy, hypoglycaemia proved refractory and the patient succumbed to his illness.

\section{Conclusion}

-Non-islet cell hypoglycaemia (NICTH) is a major complication of malignancy particularly if associated with hepatic metastases

-The aetiology is multi-factorial and includes reduced hepatic glycogen reserves, nutritional deficiency due to tumour induced cachexia and ectopic production of IGF-II which activates insulin receptors and promotes glucose utilization.

- Refractory hypoglycaemia in this context necessitates combination drug therapy but is a significant therapeutic challenge with a poor prognosis.

\begin{tabular}{|c|c|}
\hline \multicolumn{2}{|c|}{$\begin{array}{l}\text { Tumors reported to cause nonislet cell tumor } \\
\text { hypoglycemia }\end{array}$} \\
\hline Carcinomas & other tumors \\
\hline Adrenal cortex & Carcinoid \\
\hline Bile duct & Fibrosarcoma \\
\hline Breast & Fibrous tumor of the pleura \\
\hline Cervix & Hemangiopericytoma \\
\hline Colon & Hepatoma \\
\hline Esophagus & Hypernephroma \\
\hline Larynn & Lymphoma \\
\hline Lung & Leiomyosarcoma \\
\hline Owary & Liposarcoma \\
\hline Pancreas & Meningioma \\
\hline Prostate & Mesothelioma \\
\hline \multirow[t]{6}{*}{ Stomach } & Multiple myeloma \\
\hline & Neurilmoma \\
\hline & Neurofibroma \\
\hline & Neurofibrosarcoma \\
\hline & Pheochromocytoma \\
\hline & Wilm's tumor \\
\hline
\end{tabular}

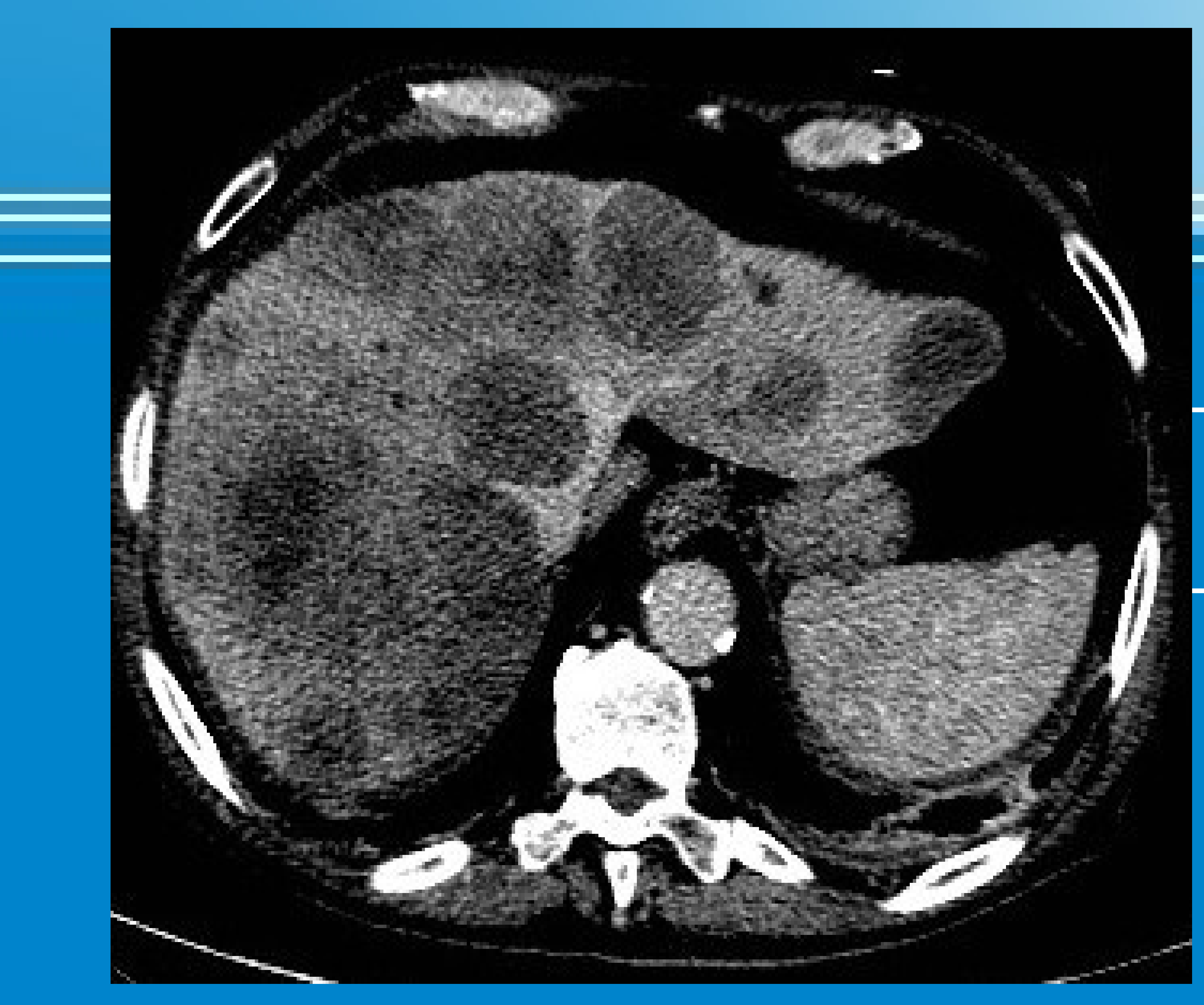

